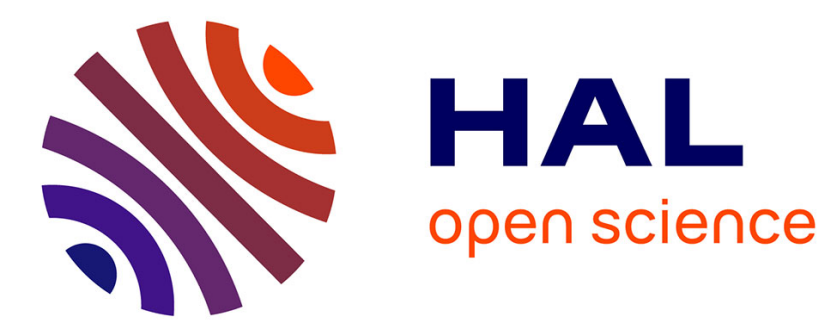

\title{
The domino effect and integrated probabilistic approaches for risk analysis
}

Q. B. Nguyen, Ahmed Mebarki, Frédéric Mercier, Ramdane Ami Saada, M. Reimeringer

\section{- To cite this version:}

Q. B. Nguyen, Ahmed Mebarki, Frédéric Mercier, Ramdane Ami Saada, M. Reimeringer. The domino effect and integrated probabilistic approaches for risk analysis. Eight International Conference on Computational Structures Technology, Sep 2006, Las Palmas, Spain. pp.27-34. hal-00719771

\section{HAL Id: hal-00719771 \\ https://hal.science/hal-00719771}

Submitted on 10 Apr 2014

HAL is a multi-disciplinary open access archive for the deposit and dissemination of scientific research documents, whether they are published or not. The documents may come from teaching and research institutions in France or abroad, or from public or private research centers.
L'archive ouverte pluridisciplinaire HAL, est destinée au dépôt et à la diffusion de documents scientifiques de niveau recherche, publiés ou non, émanant des établissements d'enseignement et de recherche français ou étrangers, des laboratoires publics ou privés. 


\title{
The Domino Effect and Integrated Probabilistic Approaches for Risk Analysis
}

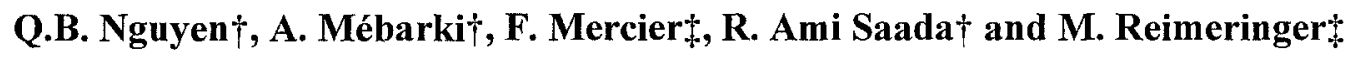 \\ $\dagger$ Laboratoire de Mécanique \\ University of Marne-la-Vallée, France \\ \$Institut National de l'Environnement Industriel et des Risques \\ (INERIS), France
}

\begin{abstract}
The paper develops a probabilistic approach in order to deal with domino effects that may occur in industrial facilities: an explosion or accident may generate various sets of projectiles that may impact other existing facilities (tanks under high-pressure, etc) and may generate other sets of projectiles and so on. Three main parts are considered:

- Source term: for the first set of generated projectiles, probabilistic distributions are considered for the number, masses, velocities, departure angles, geometrical form, dimensions, and constitutive materials properties. The authors have collected existing models from the literature.

- Target term: for the set of impacted targets, probabilistic distributions are considered for the number of impacting projectiles, velocities, incidence angles and energy at impact, constitutive materials properties, dimensions of the impacted targets, and projectiles penetration depths into the targets. In this paper, new models for the impact are proposed to calculate the penetration depth after impact: case of cylindrical rods impacting rectangular plates, both are metal made. The theoretical results are compared to the experimental data (4 data sets) collected from the literature with the following features: projectiles mass ranging from $0.1 \mathrm{~g}$ up to $250 \mathrm{~kg}$, projectiles velocity ranging from $10 \mathrm{~m} / \mathrm{s}$ up to $2100 \mathrm{~m} / \mathrm{s}$, projectiles diameters ranging from $1.5 \mathrm{~mm}$ up to $90 \mathrm{~mm}$, target strength ranging from $300 \mathrm{MPa}$ up to $1400 \mathrm{MPa}$ and incidence angles ranging from $0^{\circ}$ up to $70^{\circ}$.

- Domino effect term: evaluation of the risks of second set of explosions that may take place in the impacted components. Monte Carlo simulations are used in order to calculate the different probabilities: probability of impact, distribution of the penetration depth and probability of domino effect.
\end{abstract}

Keywords: domino effect, industrial explosions accident, mechanical impact, tanks, projectile, penetration, perforation, risk, reliability, probabilistic methods. 


\section{Introduction}

Many types of equipment under pressure may exist in industrial installations: tanks containing gas or highly pressurized liquids, for instance. When reaching critical levels of overpressure, overheating or mechanical demand, a catastrophic sequence, may rise. Actually, the tanks may suddenly explode in many fragments that should be considered as projectiles threatening the other equipments or installations in their neighbourhood, [13]. These projectiles can impact other equipments, penetrating them partially or perforating them. Depending on these degrees of perforation, new accidents may take place in the impacted objects, leading therefore to series of accidents known as domino effect. Many studies deal with the prevention or mitigation of the domino effect consequences, [14-17].

The present paper develops a global methodology in order to study the domino effect, detailing in a probabilistic framework all the components of the catastrophic sequence. The probabilistic distributions of the whole involved parameters are derived from existing bibliography and data or are postulated otherwise: fragment number, initial velocity, initial angles, mass, geometrical form... The trajectory of the projectiles and their impact with surrounding objects are also investigated. Mechanical models are developed in order to calculate the penetration depth and the mechanical damage caused to the impacted targets. The risk or probability of domino effect occurrence is calculated by Monte Carlo simulations, $[9,10,24,28]$.

\section{General framework}

The overall domino effect sequences are described in Figure 1a. This domino effect may be detailed by describing each of the elementary steps or cycles. Each cycle requires three elementary components (steps): a source term (explosion or generation of the fragments), the projectiles trajectory term (angles, velocities and displacements from the source), and the target term (impact and interaction between the projectile and the target), see Figure $1 \mathrm{~b}$.

Thus, each elementary branch of the domino effect requires three detailed steps, see Figure 2:

- The generation of the preliminary accident that gives rise to the fragments projection: the factory site contains one or more tanks under pressure of gas, heated liquids or mechanical aggression. Under the effect of the overpressure due to the gas or the liquid, or the mechanical aggression, the tank may explode and generate fragments. This probabilistic term describes the probability of generation of the fragments, $P_{\text {gen }}$.

- In their trajectory, the fragments may hit other equipment in their neighbourhood. This possibility of impact is defined by the probability of impact, $\mathbf{P}_{\text {imp }}$. 
- The impacted targets may suffer partial damage or complete penetration of the projectile. Depending on the targets properties and their critical damage, an explosion may rise in this targeted element. The probability of explosion after impact, $\mathrm{P}_{\text {rup}}$, defines the risk of another branch occurrence in the domino effect sequence.

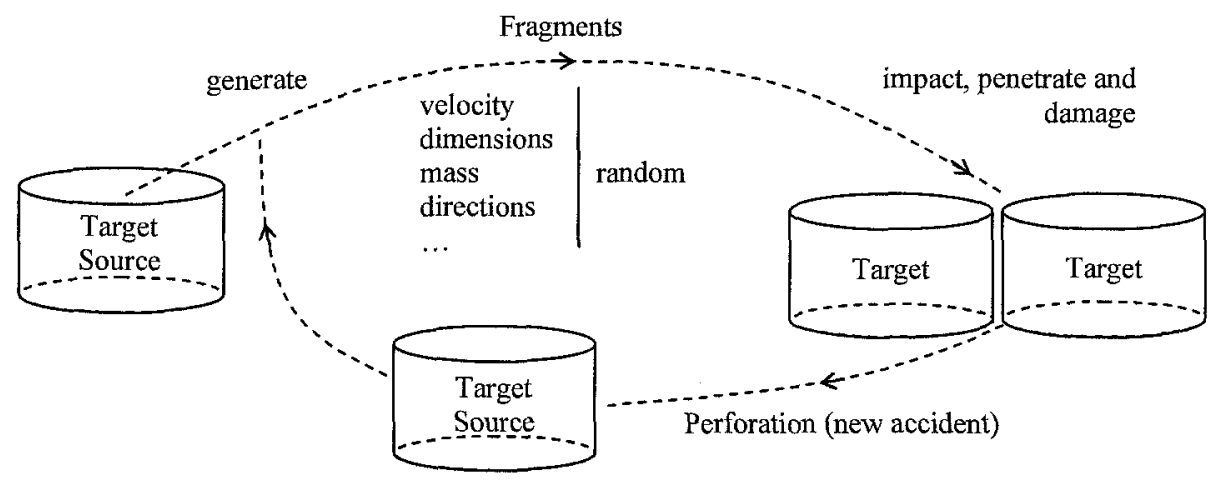

(a)

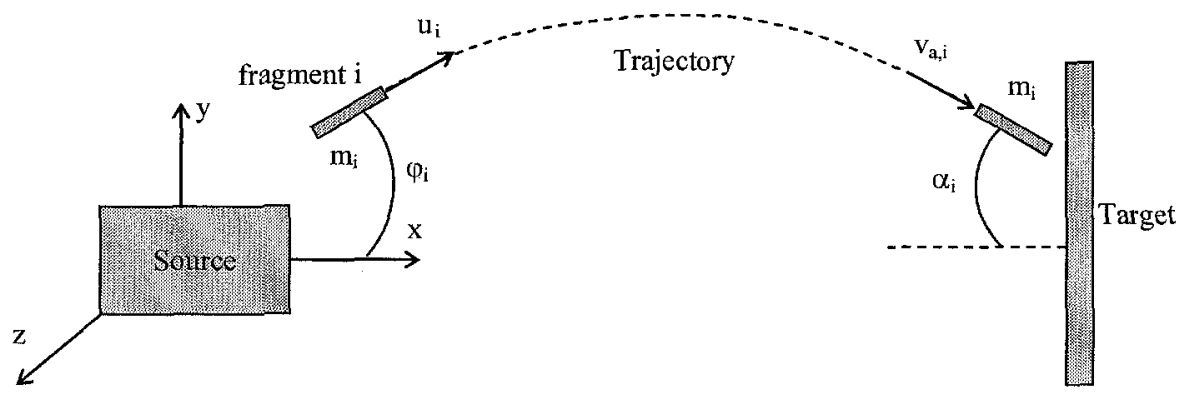

(b)

Figure 1: Diagram of the effect domino (a) total view; (b) cyclic view

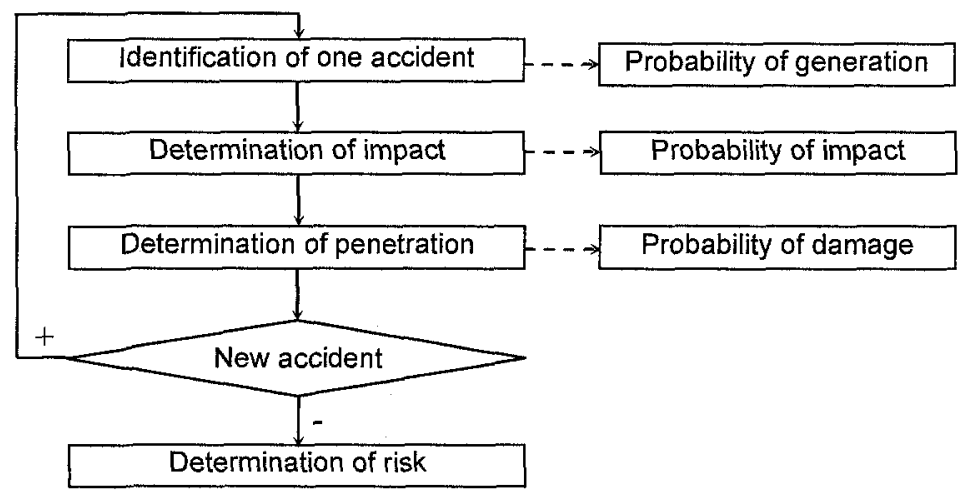

Figure 2: Domino effect sequences 


\section{Analyze reliability and probability of crisis}

As a first step, the present paper focuses mainly on the case of one elementary sequence in the domino effect sequences. The target is supposed to be a planar metal plate. The projectile is supposed to be a metal rod, see Figure 1b. The risk of domino effect occurrence may be expressed as:

$$
\mathrm{P}_{\mathrm{f}}=\mathrm{P}_{\text {gen }} \times \mathrm{P}_{\text {imp }} \times \mathrm{P}_{\text {rup }}
$$

where: $\mathrm{P}_{\mathrm{gen}}=$ probability of generation of projectiles (source term), $\mathrm{P}_{\mathrm{imp}}=$ probability of impact, $\mathrm{P}_{\text {rup }}=$ probability of failure of the impacted target.

In fact, the general expression is:

$$
P_{f}=P(E \leq 0)=\int_{E \leq 0} f_{e}(e) \cdot d e=\iint_{R-S \leq 0} f_{r}(r) \cdot f_{s}(s) \cdot d r \cdot d s \text {, and } E=R-S
$$

With: $R=$ random resistance (which values are $r$ ), $S=$ random mechanical demand (which values are $s$ ), $\mathrm{P}_{\mathrm{f}}=$ probability of failure, $\mathrm{E}=$ limit state function $(\mathrm{E}<0$ : defines the failure domain, $\mathrm{E}>0$ : defines the safety domain, $\mathrm{E}=0$ : defines the limit state surface).

The risk evaluation requires the knowledge of the probability density functions $\mathrm{f}_{\mathrm{r}}($.$) and \mathrm{f}_{\mathrm{s}}($.$) .$

\section{Source terms}

\subsection{Source term features}

An industrial accident may generate several fragments having various forms, sizes, initial velocity, and initial departure angles. It is therefore required to define correctly the distributions and the features of the source term: fragments number, fragments forms and size, their masses, their initials departure angles (horizontal and vertical angles), their initial velocities at departure, and their aerodynamic coefficients (lift and drag coefficients).

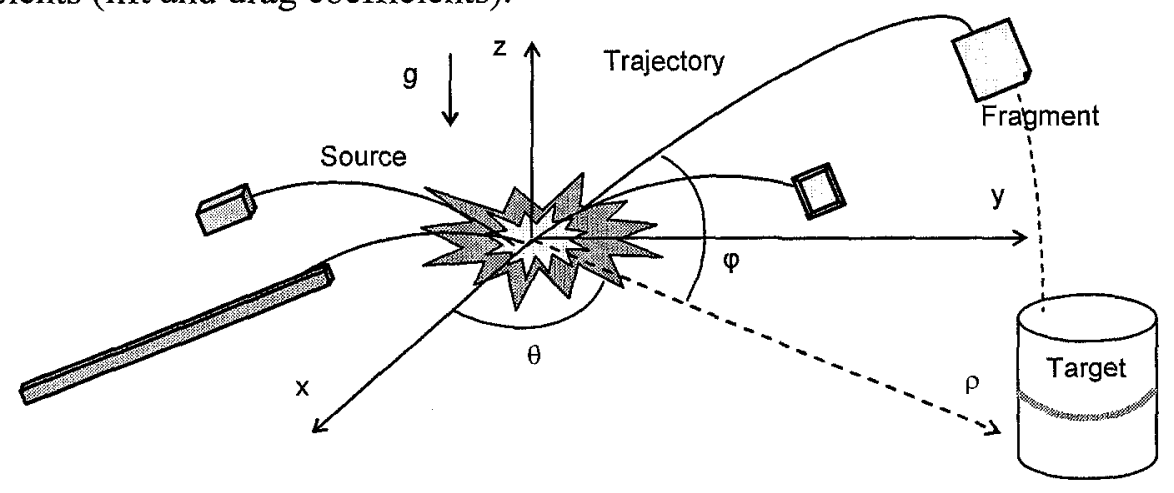

Figure 3: Explosion generates several fragments [26] 


\subsection{Fragment number}

A tank explosion may generate one or many fragments according to the critical pressure, to the cracks propagation, to the tank constitutive material and to the connection between the elementary mechanical components. According to scientific reports collected from INERIS [18-23], the typical explosion (BLEVE) of a cylindrical tank produces a limited number of massive fragments: generally two or three, and very seldom more than four or five.

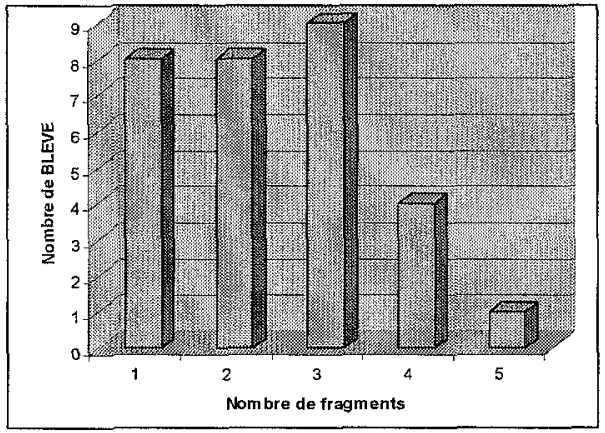

Figure 4: Number of accidents (BLEVE) vs. fragments number [22]

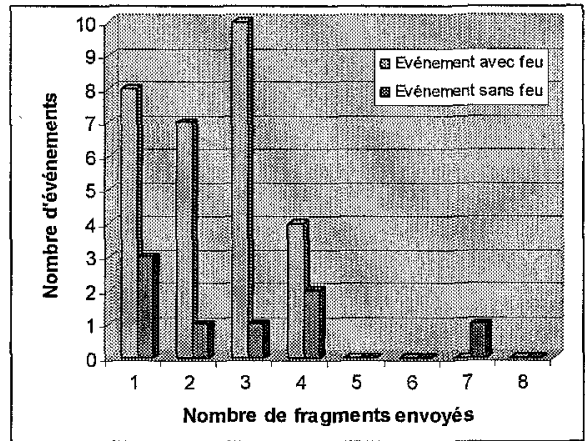

Figure 5: Number of fragments flying as projectiles from the cylindrical tank under gas or liquid pressure [17]

Holden [17] quotes, for 31 BLEVEs having produced 76 fragments, an average number of 2.45 fragments, corresponding to 2.87 without fire production and 2.34 with fire production. In fact, the accidents generate 1,2,3 or 4 fragments (except a case without fire). A test of BLEVE, with a carriage of $45 \mathrm{~m}^{3}$ containing 5 tons of propane, produced 4 fragments from the tank envelop and the BLEVE tests on propane reserves of 400 litres produced 1 up to 3 fragments [20-23].

Moreover, according to the analysis and the experiments of Baum [6], the rupture starts with the circumferential welding and terminates with the split of bottom part of the tank (without or with a part of the ring). Therefore, it generates 2 up to 4 fragments: bottom of the tank (with or without the ring) and pieces of the ring. The size of the tank does not have an influence on the fragments number. Larger the tank, larger the fragments, but the size of the tank does not have incidence on the number of fragments [22].

For the cylindrical tank, Hauptmanns [15] finds out that the number of fragments follows a log normal distribution.

Therefore, in the present study, the fragment number is supposed to follow a log normal distribution, truncated within the interval [1 up to 4].

\subsection{Fragments shape}

The form of the fragments depends mainly on both the rupture type and the cracks propagation in the tank. However, the cracks initiates in the circumferential part and propagates until it cuts one of the two end-caps; then, it unfolds the ring [18, 22, 23]. 
It may also happen that the end-cap does not split from the ring, the ring remains linked to the end-cap as a rocket [23]. The ring generates sometimes 1 or 2 pieces [22].

The fragment shape is also variable and unpredictable. Holden [17] gives a mere classification of the fragments types according to the number of linked caps and number of circumferential cracks; the types of fragments are similar to those collected from INERIS.

According to Gubinelli [14], some types of fragments of a BLEVE might be classified as: cylindrical, end-cap, end-cap attached to the ring, and the tube. Baum [7] has studied also the end-cap (in case of constrained tanks) and the end-cap with the cylindrical binding ring (in case of unrestrained tank).

In the present study, it is therefore assumed that the fragments are one among the end-cap, the ring attached to the end-cap, or the flattened piece of the ring (the plate).

\subsection{Fragment mass}

There is no suitable information available, in the existing literature, about the fragments masses distribution. Therefore, as a first step, all the fragments are supposed to have the same mass. Their form is supposed to be a piece of sphere [16]. On the other hand, for cylindrical tanks, Hauptmanns [15] shows that the fragments masses factor (ratio between the fragment mass / total mass) follows a Beta distribution.

However, when the shape and the size of a fragment are known, the fragment mass may easily be calculated.

In the present study, the fragment masses are then derived from the shape and the size of each fragment, as fragment size is supposed to follow a log normal distribution.

\subsection{Initial velocity}

It is also required to define the velocity of the fragments resulting from an industrial accident (explosion, etc...). Aquaro [1] performed experimental studies on a reduction scale with mass fragments thronging within the interval [20 up to 200] $\mathrm{kg}$ and velocity ranging within the interval [100 up to 30$] \mathrm{m} / \mathrm{s}$, respectively. The fragment velocity might therefore be derived according to the fragment mass and the pressure before combustion.

Actually, the initial velocity of the fragments requires the knowledge of the kinetic energy $\left(E_{k}\right)[15,16]$. For this purpose, $E_{k}$ is deduced from the total energy (E), on the basis of the methods suggested by Baker and Baum [2,5].

From experimental studies, Baum [4] proposed the adequate formula for the endcap velocity of vertical cylindrical tank being detached and being accelerated by the exit of gas due to failure of the circumferential welding, see Figure 6 . They correspond to the "zero mass of end-cap" model, the "broad mass of end-cap" model and the "velocity limit of the end-cap" model. 


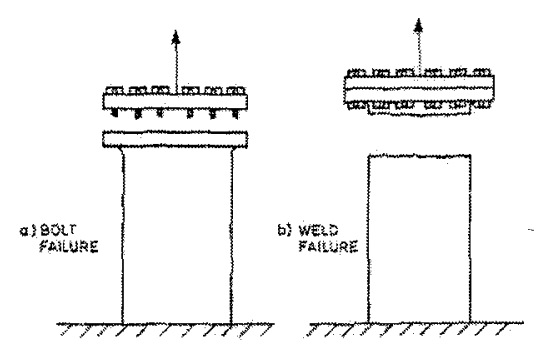

Figure 6: End-cap of the vertical tank detached [4]

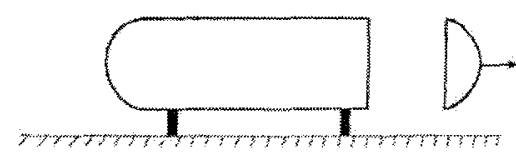

(a)

(a)

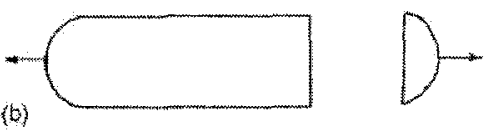

Figure 7: (a) Horizontal constrained tank; (b) Unconstrained tank [7]

From other tests, Baum [7] investigated the end-cap velocity according to the kind of materials contained in the tank and the temperature of the substances. Two types of fragment are analyzed: end-cap and the end-cap linked to the ring (the rocket), [6]. From the results of the tests performed by Baum [5-8], the initial velocity is well described by the log normal distribution.

\subsection{Initial departure angle}

\subsubsection{Vertical angle}

From the existing literature, there is no reliable information about the horizontal angle. It is assumed therefore, as a first step, that the initial vertical angle follows a uniform distribution within the interval $\left[-90^{\circ} ; 90^{\circ}\right],[15,16]$.

\subsubsection{Horizontal angle}

From analysis of accidents that have occurred, Holden [17] investigated the distribution of the fragments initial trajectory in the tank principal axes system, see Figures $8 \mathrm{a}-\mathrm{b}$. According to the statistical analysis for 15 accidental BLEVE having produced 59 fragments [17], approximately $60 \%$ of the fragments are projected in an angular sector of $60^{\circ}$ around the axis of the tank, and the remainder is projected rather perpendicularly to the tank major axis. Also, it has been found the end-cap follow the major axis of the tank whereas the pieces belonging to the ring follow the minor axis [22]. According to Holden [17], a uniform distribution might be considered in the case of a cylindrical tank; actually the ratios of fragments horizontal departures angles, see Figure $8 \mathrm{~b}$ : $20 \%$ of the angles range within $\left[30^{\circ}\right.$ $\left.150^{\circ}\right], 30 \%$ of the angles range within $\left[150^{\circ}-210^{\circ}\right], 20 \%$ of the angles range within $\left[210^{\circ}-330^{\circ}\right]$, and $30 \%$ of the angles range within [330 -30$],[15]$.

In the present study, the initial horizontal angle are supposed to follow the uniform distribution detailed as follows: $20 \%$ of the angles range within $\left[30^{\circ}-150^{\circ}\right.$, $30 \%$ of the angles range within $\left[150^{\circ}-210^{\circ}\right], 20 \%$ of the angles range within $\left[210^{\circ}\right.$ $\left.330^{\circ}\right]$, and $30 \%$ of the angles range within $\left[330^{\circ}-30\right]$. 


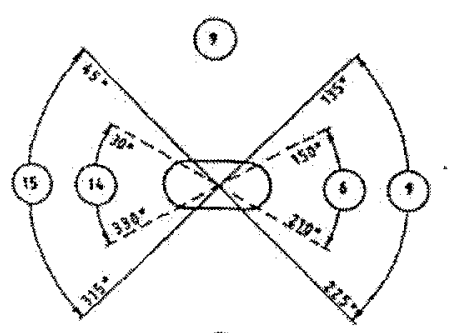

(ख)

(a)- Horizontal distribution of the fragments

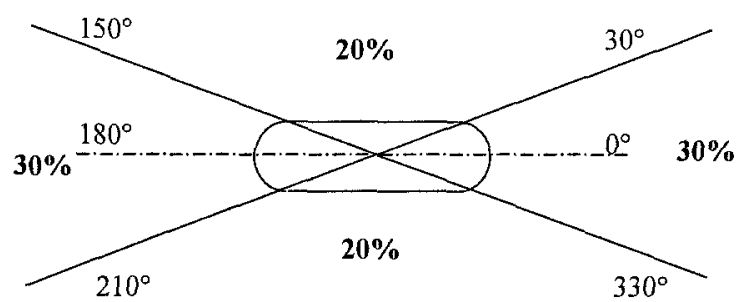

(b)- Simplified horizontal distribution of the fragments

Figure 8: Horizontal departure angles of the projected fragments, [17]

\subsection{Drag coefficient and lift coefficient}

\subsubsection{Lift coefficient, $C_{L}$}

The lift rises for dissymmetric faces of the fragment: upper surface and lower surface, [21]. Thus, the lift should be considered for the end-cap and the end-cap attached to the ring. This lift coefficient is expressed as:

$$
\mathrm{C}_{\mathrm{L}}=0.351+0.6723 . \alpha
$$

With: $\alpha=$ the inclination angle. $\mathrm{C}_{\mathrm{L}}$ is supposed to be equal to zero for the angles ranging outside the interval $\left[0^{\circ}, 10^{\circ}\right],[15]$.

In the present paper, it is assumed, as a first step, that the lift coefficient follows a $\log$ normal distribution.

\subsubsection{Drag coefficient, $C_{D}$}

The drag phenomenon depends on several factors, i.e. the geometry, the surface roughness and the orientation in respect to the velocity direction. An acceptable range values for $C_{D}$, in the case of tank end-caps, is [0.8 - 1.1] and a range values $[1.1-1.8]$ for the rings. A uniform distribution for the drag coefficient, $\mathrm{C}_{\mathrm{D}}$, might be considered within the given intervals, [15-16].

In the present study, the following hypotheses are adopted:

- For end-cap fragments, the lift coefficient follows a uniform distribution within the interval $[0.351-0.468]$ and the drag coefficient follows a uniform distribution within the interval $[0.8-1.1]$;

- For the ring, the effect of the lift can be neglected. Thus the drag coefficient follows a uniform distribution within the interval [1.1 - 1.8]. 


\section{$5 \quad$ Fragment trajectory and impact features}

The generated fragments may impact potential targets on their trajectory, being therefore a mechanical threat for these target, as it may damage it seriously. The trajectory of the projectiles has then to be exactly known.

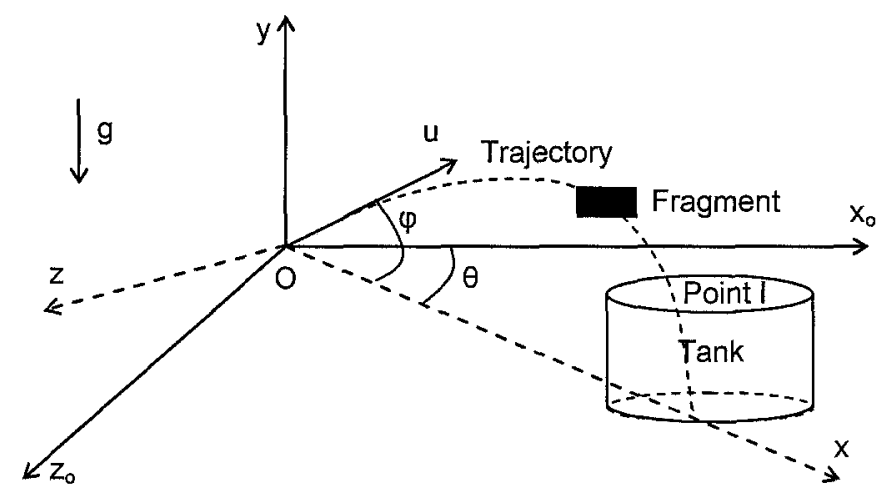

Figure 9: Trajectory of the fragment

This kind of problem has already been studied in order to investigate the possible the collision between a fragment (the projectile) and a tank (the target) in its vicinity, Hauptmanns [15-16]. The movement of the fragment has been analysed in bidimensional (2D) approach, see Figure 9. The simplified form of the possible impact analysis supposes that the fragment trajectory can be described by the trajectory of a point (its barycentre). For this purpose, Gubinelli [14] presents also the model known as "minimal distances". The simplified forms are the following: rectangular form in xy plane and circular form on xz plane.

The present study deals with the possible impact and requires also the detailed information in order to evaluate the mechanical damage caused to the targets by the impact. A three dimensional analysis is therefore considered. However, for simplification purposes at the present step, the rotation effect of the fragment during the movement is neglected. The equations of motion for the centre of the fragment are as follows, see Figure 10:

$$
\left\{\begin{array}{c}
\left(k_{D}-(-1)^{n} \cdot k_{L}\right) \dot{x}^{2}+\ddot{x}=0 \\
\left((-1)^{n} \cdot k_{D}+k_{L}\right) \dot{y}^{2}+\ddot{y}+g=0 \\
\left(k_{D}-(-1)^{n} \cdot k_{L}\right) \dot{z}^{2}+\ddot{z}=0
\end{array}\right.
$$

where: $\mathrm{n}=1$ at descending part; $\mathrm{n}=2$ at ascending part.

with: $\mathrm{k}_{\mathrm{D}}=\frac{1}{2} \frac{\rho_{\text {air }} \cdot \mathrm{C}_{\mathrm{D}} \cdot \mathrm{A}_{\mathrm{D}}}{\mathrm{m}} ; \mathrm{k}_{\mathrm{L}}=\frac{1}{2} \frac{\rho_{\mathrm{air}} \cdot \mathrm{C}_{\mathrm{L}} \cdot \mathrm{A}_{\mathrm{L}}}{\mathrm{m}} ;\left(\mathrm{k}_{\mathrm{D}}-\mathrm{k}_{\mathrm{L}}\right)=\mathrm{k}_{\mathrm{m}} ;\left(\mathrm{k}_{\mathrm{D}}+\mathrm{k}_{\mathrm{L}}\right)=\mathrm{k}_{\mathrm{p}}$

The detailed equations are described in the Appendix that presents the analytical solutions of the nonlinear differential equations system. From these equations and 
the coordinates of the potential targets, the impact occurs when exists a possible intersection between the fragment and the target equipment. If there is a possible impact, the solutions provide the coordinates of the intersection, the velocities and angles at impact.

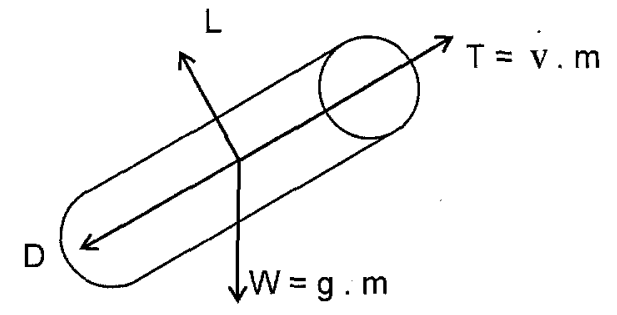

Figure 10: Forces applied to the fragment

\section{Penetration and perforation}

\subsection{Simplified mechanical model}

At the impact, the required information is:

- for the impacting projectile: its velocity of arrival $v_{p}$, its mass $m_{p}$, its shape, its size and its constitutive material properties,

- for the impacted target (metallic plate in the present study): its thickness and its constitutive material properties.

The impact may cause a partial damage to the target. It may also cause a total penetration or a critical damage that may cause explosion of the target if concerned, see Figure 11.

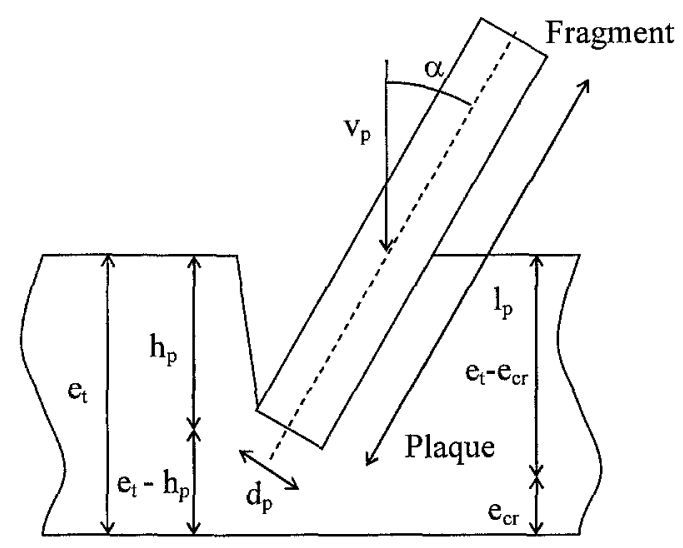

Figure 11: Impact of a projectile (fragment) on a target (a plate)

The fragment may penetrate inside the target and creates a crater, reducing therefore the residual resisting thickness of the target ate the impacted zone. Three scenarios might be considered, see Figures 11-12: 
- Partial penetration in the critical domain: The fragment penetrates partially but the residual thickness of the plate at the zone of impact remains larger than critical thickness of the plate, $\mathrm{e}_{\mathrm{cr}}$ (Curve 1, see Figure 12),

- Partial penetration beyond the critical domain: The fragment penetrates partially the target but the residual thickness ranges within the critical interval [0, $\left.\mathrm{e}_{\mathrm{cr}}\right]$ (Curve 2, Figure 12). Therefore, due to the effect of the gas or liquid internal pressure, the target may not resist this high pressure: cracks may appear with possible explosion of this damaged target.

- Complete perforation: The kinetic energy of the fragment is so large that the projectile may penetrate completely the target, and cause explosion of the target (Curve 3, Figure 12).

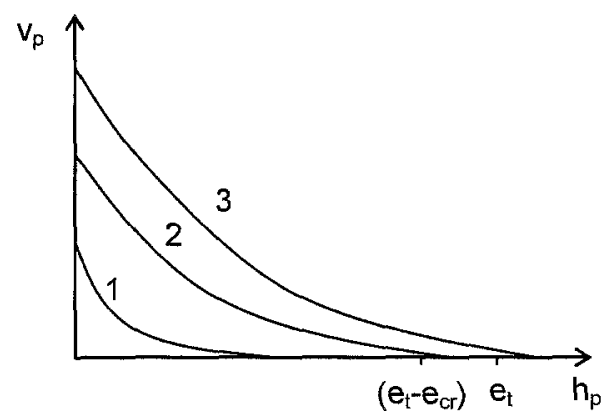

Figure 12: Relationship between the projectile velocity and the penetration depth 1 - Partial penetration in the critical domain, 2 - Partial penetration beyond the critical domain, 3 - Complete perforation

The last two cases also represent threaten therefore the integrity of the impacted target after the impact. For this purpose, mechanical models should be run in order to calculate the penetration depth and compare the residual thickness to the threshold thickness that may avoid the explosion of the impacted target.

For this purpose, various experimental data for this kind of impacts are collected from the existing literature $[9,10,24-28]$. For instance, a mechanical model is developed in order to calculate the penetration depth for given ranges of the projectiles velocities: for instance, Bless [9], corresponds to a velocity of almost $\sim 2.15 \mathrm{~km} / \mathrm{s}$. Many other models have also been developed and compared to the experimental data, Neilson [28], BRL and SRI models, [10, 24]. The authors have recently issued a mechanical model that evaluates the penetration depth, $h_{p}$, in the case of metallic targets and metallic rods as projectiles, Mébarki [25-27]. The penetration depth depends on the incidence angle $\alpha$ of the projectile at the impact, see Figure 11:

- penetration depth for the case $\alpha \neq 0$

$$
h_{p}=\frac{-d_{p} \cdot \cos \alpha+\sqrt{\left(d_{p} \cdot \cos \alpha\right)^{2}+4 \cdot \tan \alpha \cdot\left(\frac{E_{c}}{f_{u} \cdot \varepsilon_{u}}\right)^{2 / 3} \cdot \frac{1}{\pi}}}{2 \cdot \tan \alpha}
$$


- penetration depth for the case $\alpha=0$

$h_{p}=\left(\frac{E_{c}}{f_{u} \cdot \varepsilon_{u}}\right)^{2 / 3} \cdot \frac{1}{\pi \cdot d_{p}}$

With the kinetic energy, $E_{c}=\frac{m_{p} \cdot v_{p}^{2}}{2}$

\subsection{Resistance}

The realization of the random variable resistance $r=e_{t}-e_{c r}$ comprises a random variable, and a constant, $\mathrm{e}_{\mathrm{cr}}$. In first approach, It makes it possible to suppose that the random variable, and, follows the normal law $\left(\mu_{\mathrm{e}}, \sigma_{\mathrm{e}}\right)$. Thus the random variable $\mathrm{r}$ also follows the normal law $\left(\mu_{e}-e_{c r}, \sigma_{e}\right)$.

\section{Application and numerical simulation}

In order to evaluate the risk of domino effect, when dealing with industrial risks, Monte Carlo simulations have been performed with the following hypotheses and probabilistic distributions:

- the fragment number follows a log normal distribution,

- the type of the fragments: end-cap of tank, end-caps of tank attached to the ring and the flattened ring are considered,

- the fragment mass is derived from the knowledge of the shape and the size of each fragment, while it is supposed that the size follows is a lognormal random variable,

- dimensions of the fragment follow a Gaussian distribution $\mathrm{N}\left(\mu_{\mathrm{dp}}, \sigma_{\mathrm{dp}}\right)$,

- the departure velocity of the fragments follow a Gaussian distribution $N\left(\mu_{u}\right.$, $\sigma_{\mathfrak{u}}$ ),

- the departure vertical angle follows a uniform distribution within the interval $\left[-90^{\circ} ; 90^{\circ}\right]$,

- the departure horizontal angle follows a uniform distribution within each interval, i.e. $30^{\circ}-150^{\circ}: 20 \% ; 150^{\circ}-210^{\circ}$ : $30 \% ; 210^{\circ}-330^{\circ}: 20 \% ; 330^{\circ}-30^{\circ}$ : $30 \%$,

- the lift coefficient pressure follows a uniform distribution within the interval [0.351;0.468],

- the drag coefficient follows a uniform distribution within the interval [0.8; $1.1]$.

Furthermore, the risk evaluation relies on the following models and sets of hypotheses:

- Impact analysis: the possible impact is analysed for the case of various shapes of the projectiles or targets (ellipsoids, cylinders, rectangles), Wang [30]. The data expected at this stage are: possibility of impact, velocity and angles at impact. Probability of impact might then be evaluated by Monte Carlo simulations. 
- The mechanical damage at impact by using the simplified analytical model, [25-27], that calculates the penetration depth of the fragment and the probability of critical damage of the tank after impact.

The Monte Carlo simulations are performed with the following set of data and the hypotheses presented above, see Table 1.

\begin{tabular}{|c|c|c|c|}
\hline \multicolumn{2}{|c|}{ Fragments } & \multicolumn{2}{|c|}{ Target } \\
\hline \multicolumn{2}{|c|}{ Rod form } & \multicolumn{2}{|c|}{ Tank cylindrical horizontal form } \\
\hline Radius & $\approx 0.3 \times 0.2 \times 0.3(\mathrm{~m})$ & Radius & $2 \times 1 \times 2(\mathrm{~m})$ \\
\hline Length & $\approx 0.52(\mathrm{~m})$ & Length & $7(\mathrm{~m})$ \\
\hline Thickness & $0.07(\mathrm{~m})$ & Thickness & $0.07(\mathrm{~m})$ \\
\hline Initial velocity & $\approx 100-150(\mathrm{~m} / \mathrm{s})$ & Centre coordinates & $10 \times 3 \times 10(\mathrm{~m})$ \\
\hline \multicolumn{4}{|c|}{ Result } \\
\hline \multicolumn{2}{|c|}{ Probability of generation } & \multicolumn{2}{|c|}{$\begin{array}{l}100 \% \text { (assumed that an accident has } \\
\text { occurred) }\end{array}$} \\
\hline \multicolumn{2}{|c|}{ Probability of impact } & \multicolumn{2}{|c|}{$0,6 \%$ (for 30000 simulations) } \\
\hline \multicolumn{2}{|c|}{ Probability of ruin } & \\
\hline \multicolumn{2}{|c|}{ Risk } & \multicolumn{2}{|c|}{$\mathbf{0 , 4 3 \%}$ (for 182 simulations of impacts) } \\
\hline
\end{tabular}

Table 1 - Data and Monte Carlo simulations results

\section{Conclusions}

The present paper deals with the domino effect in industrial systems. The risk represents the probability of occurrence of a domino effect as a consequence of an explosion that generates projectiles. These projectiles may impact other industrial components (such as tanks) at the neighbourhood. The features of the projectiles as well as the features of the impacted targets are described within a probabilistic framework.

Three main steps are required: probabilistic analysis of the source event (probability of explosion and generation of fragments, $\left.\mathrm{P}_{\mathrm{gen}}\right)$, probabilistic analysis of the projectiles movement and their possible impact on targets (probability of impact, $\mathrm{P}_{\mathrm{imp}}$ ) and probabilistic analysis of the target damage (probability of target rupture that may cause a new sequence of projectiles generation leading to a domino effect, $\mathrm{P}_{\text {rup }}$ ).

The number of fragments, their size, their mass, their velocity at departure, and their departure angles are considered as random variables. The velocities and incidence angles at impact of potential targets are also considered as random variables. The mechanical features of the impacted targets are described as random variables.

The mechanical models developed for this purpose evaluate the residual depth of the targets and the penetration depth of the projectiles after impact.

Monte Carlo simulations are run and the risk of domino effect is evaluated. The domino effect is thus be analyzed within a probabilistic framework. For the simulations run as an example, the probability of failure effect is in the order of $4 \times 10^{-3}$. 


\section{References}

[1] Aquaro D. and Forasassi G. (1987) An experimental set up for intermediate velocity impact simulation studies related to the safety of NPP structures and components. Dipartimento di Costruzioni Meccaniche e Nucleari, University of Pisa, Italy

[2] Baker Q.A. and Baker W.E. (1991) Pros and cons of TNT equivalence for industrial explosion accidents. Proceedings of the International Conference and Workshop on Modelling and Mitigating the Consequences of Accidental Releases of Hazardous Materials, 585-597

[3] Baum M.R. (1988) Disruptive failure of pressure vessels: Preliminary design guidelines for fragment velocity and the extent of the hazard zone. Journal of Pressure Vessel Technology, 110, 168-176

[4] Baum M.R. (1995) Rupture of a gas-pressurized cylindrical vessel: the velocity of a detached end-cap. Journal of Loss Prevention in the Process Industries, Vol. 8, No. 3, pp 149-161

[5] Baum M.R. (1998) Rocket missiles generated by failure of a high pressure liquid storage vessel. J. of Loss Prevention in the Process Industries, 11, 11-24

[6] BAUм M.R. (1999-a) The velocity of end-cap and rocket missiles generated by failure of a gas pressurised vessel containing particulate material. Journal of Loss Prevention in the Process Industries, 12, 259-268

[7] BAUм M.R. (1999-b) Failure of a horizontal pressure vessel containing a high temperature liquid: the velocity of end-cap and rocket missiles. Journal of Loss Prevention in the Process Industries, 12, 137-145

[8] Baum M.R. (2001) The velocity of large missiles resulting from axial rupture of gas pressurised cylindrical vessels. Journal of Loss Prevention in the Process Industries, 14, 199-203

[9] Bless S. J., Barber J. P., Bertke R. S. and H. F. Swift (1978) Penetration mechanics of yawed rods. Int. J. Eng. Sci., 16 (11), 829-834

[10] Bukharev Y. I. and Zhukov V. I. (1995) Model of the penetration of a metal barrier by a rod projectile with an angle of attack. Combustion, Explosion and Shock Waves, 31 (3), 104-109

[11] Cozani V., Antonioni G. and Spadoni G. (2006-a); Quantitative assessment of domino scenarios by a GIS-based software tool. Journal of Loss Prevention in the process industries, 19, 463-477

[12] Cozani V., Gubinell G. and Salzano E. (2006-b) Escalation thresholds in the assessment of domino accidental events. Journal of Hazardous Materials, A129, 1-21

[13] Mercier F., Boulanger R., Mebarki A., Brunet L. and Reimeringer M. (2006) Risques liés aux impacts de fragments lors des accidents industriels. La lettre TI - Risques Industriels

[14] Gubinelli G., Zanelli S. and Cozzani V. (2004) A simplified model for the assessment of the impact probability of fragments. Journal of Hazardous Materials, A116, 175-187 
[15] Hauptmanns U. (2001-a) A procedure for analyzing the flight of missiles from explosions of cylindrical vessels. Journal of Loss Prevention in the Process Industries, 14, 395-402

[16] Hauptmanns U. (2001-b) A Monte-Carlo based procedure for treating the flight of missiles from tank explosions. Probabilistic Engineering Mechanics, 16, 307-312

[17] Holden P.L. and Reeves A.B. (1985) Fragment hazards form failures of pressurised liquefied gas vessels. Institution of Chemical Engineers Symposium Series, 93, 205-220

[18] INERIs (1993) Effets mécaniques de projectiles impactant des sphères de gaz liquéfié. Département Sécurité Environnement Sûreté, No. 931934.0/PCL/PCL

[19] INERIs (1995) Analyse du choc d'un projectile sur un réservoir calorifuge de GPL. Département Sécurité Environnement Sûreté, No. 93-18699-SES/JPL$\mathrm{HN}$

[20] INERrs (2002) Méthode pour l'Identification et la Caractérisation des effets Dominos. Rapport final, No Ineris-DRA-2002-25472

[21] INERIs (2004) Les éclatements de réservoirs, Phénoménologie et modélisation des effets. Direction des Risques Accidentels, No Ineris-DRA-2004-46055

[22] INERIs (2005) Calculs des effets mécaniques d'un BLEVE de citerne ferroviaire. Rapport d'étude, No Ineris-DRA-72293

[23] INERIs (2006) Etude de la tenue mécanique d'un talus à une onde de souffle et un impact. Rapport d'étude, No Ineris-DRA/REST-72677

[24] Lepareux M., Jamet Ph., Matheron Ph., Lieutenant J. L., Couilleaux J., Duboellee D. and Aguilar J. (1989) Experimental and numerical studies of impacts on stainless steel plates subjected to rigid missiles at low velocity. Nuclear Engineering and Design, 115, 105-112

[25] Mebarki A. (2004) Modèle d'atténuation sismique : prédiction probabiliste des pics d'accélération, RFGC - Revue Française de Génie Civil, Hermès Ed., 8 (9-10) 1071-1086

[26] Mebarki A., Ami Saada R., Nguyen Q.B., Mercier F., Meftah F., Reimeringer M. (2005) Mechanical behavior of metallic plates under metallic rods impact and industrial risks, Conference in Chennai, 01-06 December 2005, India

[27] Mebarki A., Nguyen Q.B., Mercier F., Ami SaAda R., Meftah F., Reimeringer M. (2006) A probabilistic model for the vulnerability of metal plates under the impact of cylindrical projectiles, Journal of Loss Prevention in the Process Industries (in Press)

[28] NeILson A. J. (1985) Empirical equations for the perforation of mild steel plates. International Journal of Impact Engineering 3 (2), 137-142

[29] Strang G. (1986) Linear Algebra and its Applications (book). Introduction to Applied Mathematics

[30] WANG W., WANG J., KIM M. (2001) An algebraic condition for the separation of two ellipsoids. Computer Aided Geometric Design, 18, 531-539 


\section{Appendix}

\section{Analytical solutions of motion equations system}

- For the assembled part of the trajectory

o Formulas $\mathrm{x}, \mathrm{z}$

- $\mathrm{k}_{\mathrm{m}}=0: \mathrm{x}=\mathrm{u}_{\mathrm{x}} \cdot \mathrm{t} \rightarrow \mathrm{t}=\frac{\mathrm{x}}{\mathrm{u}_{\mathrm{x}}}$

- $\mathrm{k}_{\mathrm{m}} \neq 0, \mathrm{u}_{\mathrm{x}}=0: \mathrm{x}=0$, no movements on axis $\mathrm{X}$

- $\mathrm{k}_{\mathrm{m}} \neq 0, \mathrm{u}_{\mathrm{x}}>0: \mathrm{x}=\frac{\ln \left(\mathrm{u}_{\mathrm{x}} \cdot \mathrm{k}_{\mathrm{m}} \cdot \mathrm{t}+1\right)}{\mathrm{k}_{\mathrm{m}}} \rightarrow \mathrm{t}=\frac{\mathrm{e}^{\mathrm{x} \cdot \mathrm{k}_{\mathrm{m}}}-1}{\mathrm{k}_{\mathrm{m}} \cdot \mathrm{u}_{\mathrm{x}}}$

- $\mathrm{k}_{\mathrm{m}} \neq 0, \mathrm{u}_{\mathrm{x}}<0: \mathrm{x}=-\frac{\ln \left(-\mathrm{u}_{\mathrm{x}} \cdot \mathrm{k}_{\mathrm{m}} \cdot \mathrm{t}+1\right)}{\mathrm{k}_{\mathrm{m}}} \rightarrow \mathrm{t}=\frac{1-\mathrm{e}^{-\mathrm{x} \cdot \mathrm{k}_{\mathrm{m}}}}{\mathrm{k}_{\mathrm{m}} \cdot \mathrm{u}_{\mathrm{x}}}$

- Formulas y

- $\mathrm{k}_{\mathrm{p}}=0: \mathrm{y}=-\frac{1}{2} \cdot g \cdot \mathrm{t}^{2}+\mathrm{u}_{\mathrm{y}} \cdot \mathrm{t} \rightarrow \mathrm{t}=\frac{-\mathrm{u}_{\mathrm{y}} \pm \sqrt{\mathrm{u}_{\mathrm{y}}^{2}-2 \cdot g \cdot \mathrm{y}}}{\mathrm{g}}$

- $k_{p}>0: y=\frac{1}{2 \cdot k_{p}} \ln \left(u_{y} \sqrt{\frac{k_{p}}{g}} \cdot \sin \left(\sqrt{g \cdot k_{p}} \cdot t\right)+\cos \left(\sqrt{g \cdot k_{p}} \cdot t\right)\right)^{2}$

- $\mathrm{k}_{\mathrm{p}}<0$ :

$y=-\frac{1}{k_{p}}\left(\sqrt{-k_{p} \cdot g} \cdot t+\ln 2+\frac{1}{2} \cdot \ln \left(\frac{\sqrt{g}}{e^{2 \sqrt{-k_{p} \cdot g} \cdot t} \cdot\left(u_{y} \sqrt{-k_{p}}-\sqrt{g}\right)-\sqrt{g}-u_{y} \sqrt{-k_{p}}}\right)^{2}\right)$

- For the descending part of the trajectory

o Formulas $\mathrm{x}, \mathrm{z}$

- $k_{p}=0: x=u_{P x} \cdot\left(t-t_{P}\right)+x_{P} \rightarrow t=\frac{x-x_{P}}{u_{P x}}+t_{P}$

- $\mathrm{k}_{\mathrm{p}} \neq 0, \mathrm{u}_{\mathrm{Px}}=0: \mathrm{x}=\mathrm{x}_{\mathrm{P}}$, pas de mouvements sur l'axe $\mathrm{x}$

- $\mathrm{k}_{\mathrm{p}} \neq 0, \mathrm{u}_{\mathrm{Px}}>0$ :

$$
x=x_{P}+\frac{\ln \left(u_{P_{x}} \cdot k_{p} \cdot\left(t-t_{P}\right)+1\right)}{k_{p}} \rightarrow t=\frac{e^{\left(x-x_{P}\right) \cdot k_{p}}-1}{u_{P x} \cdot k_{p}}+t_{P}
$$

- $\mathrm{k}_{\mathrm{p}} \neq 0, \mathrm{u}_{\mathrm{Px}}<0$ :

- Formulas y

$$
x=x_{P}-\frac{\ln \left(-u_{P x} \cdot k_{p} \cdot\left(t-t_{P}\right)+1\right)}{k_{p}} \rightarrow t=\frac{1-e^{-\left(x-x_{P}\right) \cdot k_{p}}}{u_{P x} \cdot k_{p}}+t_{P}
$$

- $\mathrm{k}_{\mathrm{m}}=0$ :

$$
y=-\frac{1}{2} \cdot g \cdot t^{2}+g \cdot t_{P} \cdot\left(t-\frac{1}{2} \cdot t_{P}\right)+y_{P} \rightarrow t=t_{P} \pm \frac{\sqrt{2 \cdot g \cdot\left(y_{P}-y\right)}}{g}
$$


- $\mathrm{k}_{\mathrm{m}}<0: \mathrm{y}=\mathrm{y}_{\mathrm{P}}+\frac{1}{2 \cdot \mathrm{k}_{\mathrm{m}}} \cdot \ln \left(\left(\cos \left(\sqrt{\mathrm{g} \cdot \mathrm{k}_{\mathrm{m}}} \cdot\left(\mathrm{t}-\mathrm{t}_{\mathrm{P}}\right)\right)\right)^{2}\right)$

- $\mathrm{k}_{\mathrm{m}}>0$ :

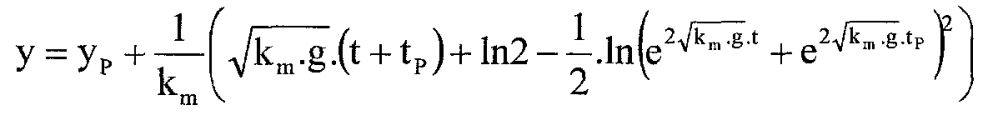

With $u_{x}, u_{y}, u_{z}$, initial velocities at the departure point $O$ and $x_{P}, y_{P}, z_{P}, t_{P}$, coordinates and time at the maximum point of the fragment barycentre trajectory. 